\title{
Rancang Bangun Penghitung Jumlah Orang dalam Suatu Ruangan menggunakan Protokol MQTT pada Internet of Things berbasis Raspberry Pi
}

\author{
Fitria Suryatini $^{1}$, Afaf Fadhil Rifai ${ }^{2}$, Susetyo Bagas Bhaskoro ${ }^{3}$ \\ 1,2,3 Jurusan Teknik Otomasi Manufaktur dan Mekatronika, Politeknik Manufaktur Bandung, Bandung 40135 \\ ${ }^{1}$ E-mail : fitria@ae.polman-bandung.ac.id \\ ${ }^{2}$ E-mail : afaffadhil@gmail.com \\ ${ }^{3}$ E-mail : Bagas@ae.polman-bandung.ac.id
}

\begin{abstract}
ABSTRAK
Jumlah orang dalam suatu ruangan menjadi hal yang penting untuk diperhatikan terutama di era pandemi seperti sekarang ini. Jumlah orang tidak boleh melebihi kapasitas maksimal ruangan tersebut. Oleh karena itu, penelitian ini bertujuan untuk membuat sistem penghitung jumlah orang dalam suatu ruangan yang dilengkapi dengan alarm peringatan jika jumlah orang melebihi kapasitas maksimal yang dapat ditentukan melalui aplikasi Android oleh pengelola ruangan. Selain itu, pengelola ruangan dapat memantau jumlah orang serta dapat menyala-matikan lampu melalui aplikasi Android berbasis IoT menggunakan protokol MQTT. Sensor PIR digunakan sebagai pendeteksi orang yang masuk dan keluar ruangan. Raspberry Pi 3 model B+ digunakan sebagai kontroler dan MQTT Client yang mengirim dan menerima data dari dan ke MQTT Client lainnya yaitu Android yang sudah terinstal aplikasi sistem penghitung jumlah orang melalui MQTT Broker HiveMQ. Hasil pengujian menunjukkan sistem berhasil menghitung jumlah orang dalam ruangan $8 \times 7 \times 3$ meter dengan kelembapan $60-80 \%$ mendapatkan tingkat akurasi $100 \%$ dan memberikan alarm peringatan jika jumlah orang melebihi kapasitas maksimal yang telah ditentukan. Data yang dikirimkan oleh yang dikirimkan publiser dan yang diterima subcriber mencapai kesesuaian $100 \%$.
\end{abstract}

Kata Kunci

Penghitung jumlah orang, sensor PIR, Raspberry Pi 3, MQTT, HiveMQ

\section{PENDAHULUAN}

Jumlah orang dalam suatu ruangan menjadi hal yang penting untuk diperhatikan terutama di era pandemi seperti sekarang ini. Jumlah orang dalam ruangan tidak boleh melebihi $50 \%$ dari kapasitas maksimal ruangan tersebut. Oleh karena itu, perlu dibuat sebuah sistem penghitung jumlah orang dalam ruangan agar tidak melebihi kapasitasnya. Hal ini dapat memudahkan pengelola gedung untuk memantau jumlah orang dalam ruangan tersebut.

Beberapa penelitian mengenai sistem penghitung jumlah orang telah dilakukan. Penghitung jumlah orang dibuat menggunakan sensor inframerah [1]-[4]. Pada penelitian lainnya sistem penghitung jumlah orang telah dibuat menggunakan sensor PIR dan mikrokontroler Arduino dimana hasil penelitian menunjukkan sistem memiliki akurasi $100 \%$ dalam mendeteksi orang [5], [6], dan memiliki akurasi 99,88\% dalam penelitian [7]. Data hasil perhitungan jumlah orang ditampilkan pada LCD [1], [3], [4], [8], [9]. Sedangkan dalam penelitian [5] data jumlah orang dikirimkan secara nirkabel ke Laptop menggunakan komunikasi radio NRF24L01, dimana hasil pengiriman data menunjukkan bahwa data dapat dikirim ke Laptop pada jarak $\leq 4$ meter pada ruangan dengan halangan dinding.
Pada penelitian ini dikembangkan sistem penghitung jumlah orang berbasis Internet of Things (IoT) menggunakan protokol MQTT sehingga data jumlah orang dapat dimonitoring darimana saja selama terkoneksi dengan internet. Protokol MQTT pada sistem berbasis IoT telah digunakan pada berbagai aplikasi [10]-[16]. Hasil penelitian terdahulu menunjukkan sistem monitoring dengan protokol MQTT pada perangkat IoT juga memiliki delay yang kecil [11]. Dan pada pengujian integritas data, protokol MQTT memperoleh kesamaan data sebesar $100 \%$ [10].

Berdasarkan pemaparan diatas, tujuan dari penelitian ini adalah membuat sistem penghitung jumlah orang dalam suatu ruangan berbasis IoT menggunakan sensor PIR dan Raspberry Pi. Sistem dilengkapi dengan alarm peringatan jika jumlah orang melebihi kapasitas maksimal ruangan tersebut yang dapat diatur pada aplikasi Android.

\section{METODE PENELITIAN}

Metode yang digunakan dalam penelitian ini adalah metode prototyping. Tahapan-tahapannya terdiri dari: perancangan dan pembuatan sistem; perancangan dan pembuatan perangkat lunak untuk operasi kerja sistem 
yang ditanamkan ke dalam kontroler; serta perancangan dan pembuatan aplikasi android.

\subsection{Gambaran Umum Sistem}

Sistem yang dibuat pada penelitian ini adalah sistem penghitung jumlah orang dalam ruangan. Hal ini bertujuan untuk membatasi jumlah orang dalam ruangan sesuai dengan batas maksimal kapasitas ruangan yang dapat diatur dan dipantau melalui aplikasi Android oleh pengelola ruangan. Gambaran umum sistem ditunjukkan pada Gambar 1.

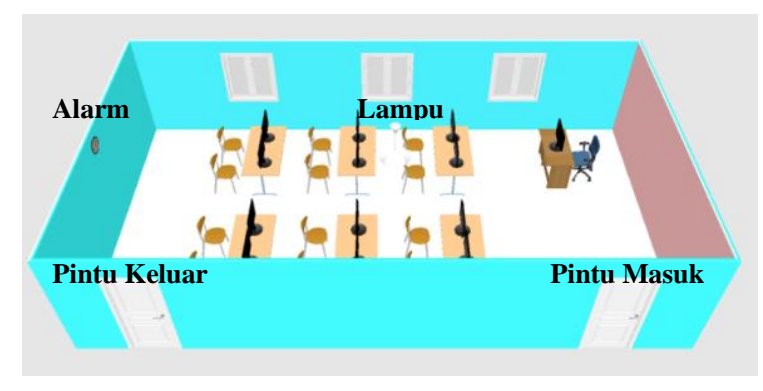

Gambar 1. Gambaran umum sistem

Ruangan terdiri dari dua buah pintu yaitu pintu masuk dan keluar yang dipasang sensor PIR pada kedua pintu. Ukuran ruangan adalah $8 \times 7 \times 3$ meter. Kelembapan ruangan pada saat pengukuran adalah $60-80 \%$. Sensor PIR digunakan untuk mendeteksi orang yang melewati pintu. Sensor yang dipasang pada pintu masuk digunakan untuk menghitung jumlah orang masuk. Sedangkan sensor yang dipasang pada pintu keluar digunakan untuk menghitung jumlah orang yang keluar ruangan. Sehingga dari kedua sensor ini dapat dihitung total orang dalam ruangan. Pada ruangan juga dipasang alarm untuk peringatan yang menyala jika jumlah orang melebihi kapasitas maksimal yang telah ditentukan sebelumnya. Sistem ini juga dilengkapi fitur tambahan untuk menyala-matikan lampu ruangan melalui aplikasi Android.

\subsection{Perancangan Sistem}

Rancangan sistem ditunjukkan pada Gambar 2. Pada sistem digunakan dua buah sensor PIR untuk mendeteksi orang masuk dan keluar ruangan, buzzer, dan lampu ruangan. Sensor PIR, buzzer, dan lampu dihubungkan ke kontroler melalui pin GPIO. Pada penelitian ini digunakan Raspberry Pi 3 model $\mathrm{B}+$ sebagai kontroler dan MQTT Client yang bertugas untuk mengolah data dari sensor PIR untuk menghitung jumlah orang pada ruangan. Dimana data ini kemudian dikirim ke MQTT Broker.

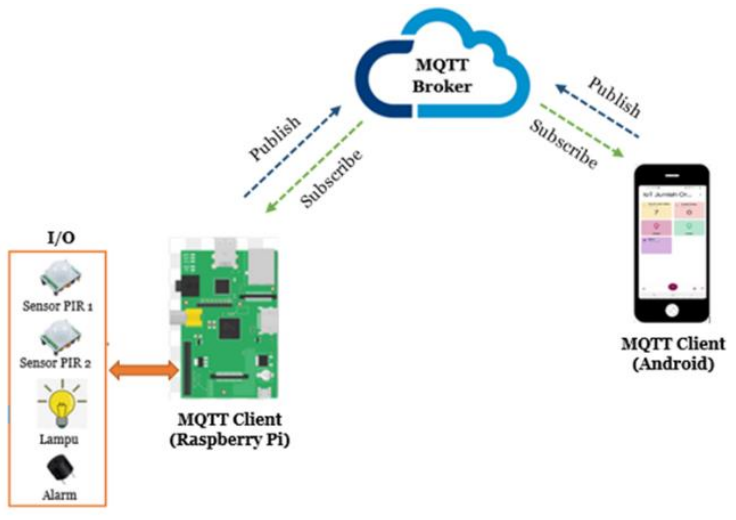

Gambar 2. Blok diagram sistem

Perangkat Iuput/Output (I/O) lainnya pada sistem ini yang dihubungkan ke GPIO Raspberry Pi adalah buzzer dan lampu. Buzzer digunakan sebagai alarm peringatan apabila jumlah orang dalam ruangan melebihi kapasitas ruangan yang telah ditentukan. Lampu digunakan untuk penerangan ruangan, dimana lampu ini dapat dihidupkan dan dimatikan melalui aplikasi android. Selain itu, aplikasi android digunakan juga untuk memantau jumlah orang dan mengatur kapasitas atau jumlah orang maksimal dalam ruangan. Android berfungsi juga sebagai MQTT Client yang mengirimkan data kapasitas maksimal dan on/off lampu. Data ini kemudian diterima oleh Raspberry Pi dan diolah untuk menyala-matikan lampu sesuai dengan data yang diterima dan mengaktifkan buzzer apabila data kapasitas maksimal telah tercapai.

\subsection{Perancangan Protokol IoT menggunakan MQTT}

Rancangan protokol IoT pada penelitian ini menggunakan protokol MQTT. Sistem kerja MQTT menerapkan Publish dan Subscribe data melalui suatu Topic tertentu. Topic merupakan pengelompokan data disuatu kategori tertentu. Publish merupakan cara suatu device untuk mengirimkan datanya ke subscribers. Subscribe merupakan cara suatu device untuk menerima berbagai macam data dari publisher. Rancangan diperlihatkan pada Gambar 3.

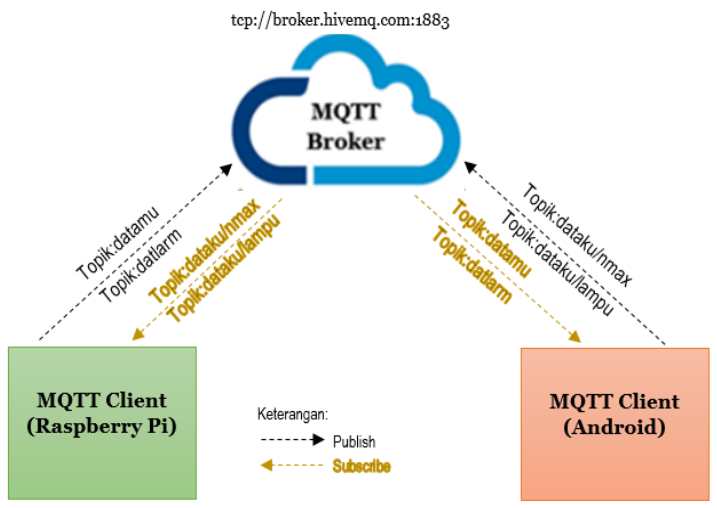

Gambar 3. Rancangan protokol IoT menggunakan MQTT 
Sistem terdiri dari dua buah MQTT Client yaitu Raspberry Pi dan Android yang sudah sudah terinstal aplikasi sistem penghitung jumlah orang ini. Kedua Client saling publish dan subscribe data melalui MQTT Broker. MQTT Broker yang digunakan pada penelitian ini adalah HiveMQ. HiveMQ merupakan MQTT broker yang memiliki standarisasi enterprise untuk kebutuhan IoT. Pada penelitian ini ditentukan beberapa topik yang berisi data yang diperlukan sistem, diantaranya: (1) topik datamu merupakan data jumlah orang yang terdeteksi sensor PIR yang dikirim oleh Raspberry Pi; (2) topik datlarm merupakan data status alarm aktif atau tidak yang dikirim oleh Raspberry $\mathrm{Pi}$; (3) topik dataku/nmax merupakan data jumlah kapasitas maksimal yang diinputkan dari aplikasi Android; dan (4) topik dataku/lampu merupakan data on/off lampu yang dikontrol dari aplikasi Android. Topik datamu dan datlarm dikirim oleh Raspberry Pi dan diterima oleh Android. Sedangkan topik dataku/nmax dan dataku/lampu dikirim oleh aplikasi Android dan diterima oleh Raspberry Pi.

\subsection{Perancangan dan Pembuatan Perangkat Lunak}

Perangkat lunak untuk sistem penghitung jumlah orang dibuat pada Raspberry Pi 3 model $\mathrm{B}+$ menggunakan bahasa pemrograman Python. Program dibuat menggunakan Visual Studio Code dan dihubungkan dengan Raspberry Pi menggunakan Ftp-Sync dan SSH Remote Access berupa Extension dari Visual Studio Code.

Sebelum program dibuat, terlebih dahulu dirancang algoritma program seperti yang ditunjukkan pada Gambar 4. Program diawali dengan inisialisasi I/O yang terhubung ke pin GPIO Raspberry Pi. I/O yang digunakan diantaranya dua buah sensor PIR, led sebagai prototyping dari lampu, serta buzzer sebagai alarm. Setelah inisialisasi dilakukan, proses berikutnya adalah menghubungkan Raspberry Pi ke MQTT Broker melalui jaringan internet. Alamat MQTT Broker yang digunakan adalah tcp://broker.hivemq.com pada port 1883. Langkah selanjutnya adalah mambaca data yang dikirim oleh Aplikasi Android melalui MQTT Broker yaitu data kapasitas maksimal ruangan pada topik dataku/nmax dan data pengaktifan lampu pada topik dataku/lampu. Jika dataku/lampu berisi pesan ON maka Raspberry $\mathrm{Pi}$ akan menyalakan lampu dengan memberikan logika High pada output GPIO yang terhubung ke lampu. Sebaliknya jika dataku/lampu berisi pesan OFF maka lampu akan mati.

Selanjutnya algoritma deteksi orang yang dijalankan sistem adalah Raspberry Pi akan membaca data sensor PIR. Jika sensor PIR pada pintu masuk mendeteksi orang yang melewati pintu (sensor PIR pada pintu masuk ON) maka data jumlah orang akan ditambah 1 $(\mathrm{n}+=1)$ dan data jumlah orang ini (n) akan dikirim pada topik datamu. Jika sensor PIR pada pintu keluar mendeteksi orang yang melewati pintu (sensor PIR pada pintu keluar ON) maka data jumlah orang akan dikurang $1(n-=1)$ dan data jumlah orang ini (n) akan dikirim pada topik datamu. Proses berikutnya adalah pengecekan apakah data jumlah orang sama dengan atau melebihi data kapasitas maksimal jumlah orang dalam ruangan. Jika jumlah orang melebihi kapasitas maksimal maka alarm akan ON, jika tidak maka alarm OFF. Data status alarm ini dikirim oleh Raspberry Pi pada topik datlarm.
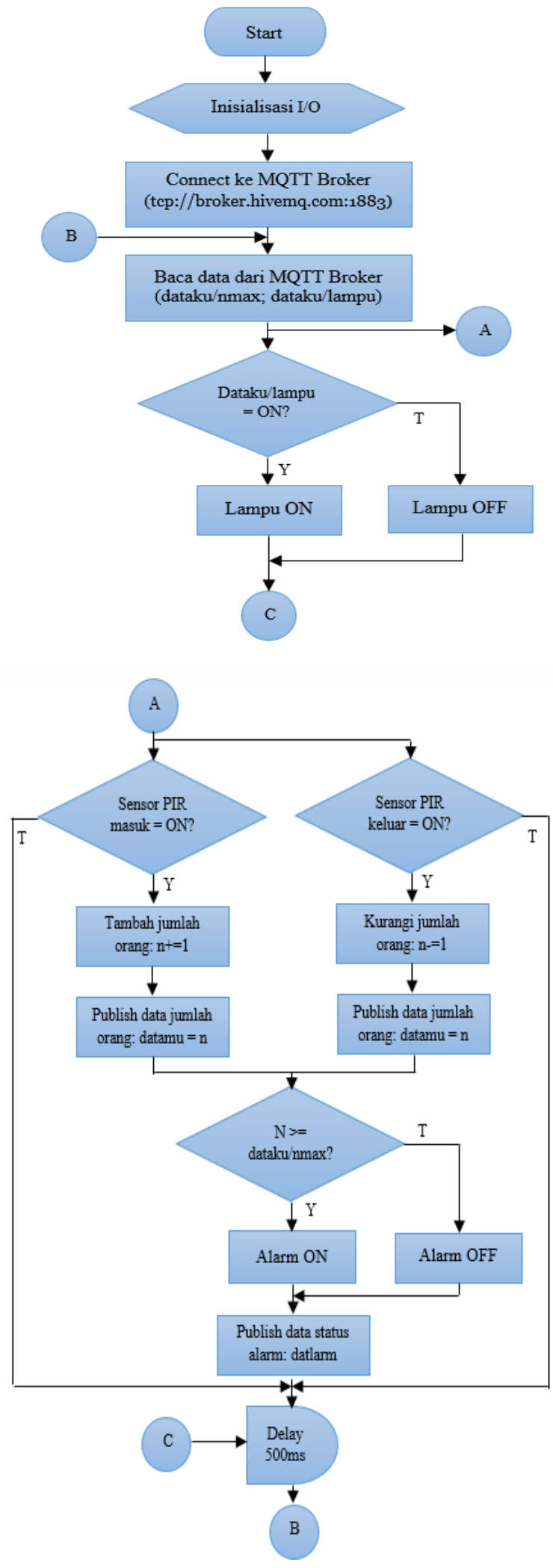

Gambar 4. Algoritma Sistem 


\subsection{Perancangan dan Pembuatan Aplikasi Android}

Pembuatan aplikasi pada Android dilakukan menggunakan aplikasi MQTT Dashboard. Tampilan aplikasi Android diperlihatkan pada Gambar 5.

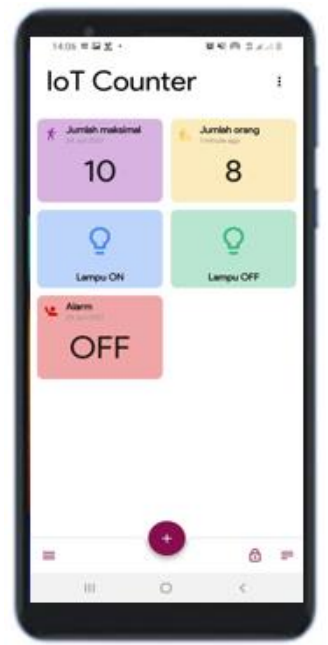

Gambar 5. Perancangan aplikasi

Fitur aplikasi Android yang dibuat terdiri dari:

1. Send text Jumlah maksimal, adalah fitur untuk mengatur kuota maksimal atau jumlah orang maksimal dalam ruangan. Pengguna dapat menginputkan nilai jumlah kapasitas maksimal dalam ruangan.

2. Text Jumlah orang, adalah tampilan untuk memonitoring jumlah orang yang sedang berada dalam ruangan tersebut. Data ini diperoleh dari hasil pembacaan sensor PIR yang dikirim melalui Raspberry Pi ke MQTT Broker.

3. Button Lampu ON, adalah tombol untuk menyalakan lampu ruangan.

4. Button Lampu OFF, adalah tombol untuk mematikan lampu ruangan.

5. Text Alarm, adalah fitur untuk menampilkan status alarm apakah on atau off.

\section{HASIL DAN PEMBAHASAN}

Sistem penghitung jumlah orang berbasis IoT pada penelitian ini diimplementasikan menggunakan sensor PIR sebagai pendeteksi orang, Raspberry Pi 3 sebagai kontroler, dan aplikasi android sebagai perangkat untuk memonitor jumlah orang dalam ruangan menggunakan protokol MQTT. Sistem dilengkapi juga dengan pengontrolan lampu ruangan. Untuk mengetahui kinerja sistem maka dilakukan pengujian sesuai dengan fitur yang tersedia. Pengujian pertama dilakukan pada fitur pengontrolan lampu. Pengujian dilakukan dengan mengaktikan tombol lampu ON dan lampu OFF pada aplikasi Android dan mengamati lampu yang terhubung pada Raspberry Pi apakah lampu menyala dan mati sesuai dengan pengaktifan tombol lampu pada aplikasi Android. Data pengujian kendali lampu terdapat pada Tabel 1.
Tabel 1. Pengujian Kendali Lampu

\begin{tabular}{ccc}
\hline Button Lampu ON & Button Lampu OFF & Lampu \\
\hline$\sqrt{ }$ & $\sqrt{ }$ & ON \\
$\sqrt{ }$ & $\sqrt{ }$ & OFF \\
$\sqrt{ }$ & $\sqrt{ }$ & OF \\
$\sqrt{ }$ & $\sqrt{ }$ & ON \\
$\sqrt{ }$ & $\sqrt{ }$ & OFF \\
$\sqrt{ }$ & $\sqrt{ }$ & ON \\
& & OFF \\
\end{tabular}

Keterangan: $\sqrt{ }=$ diaktifkan

Hasil pengujian kendali lampu yang ditunjukkan pada tabel 1 menunjukkan semua data lampu ON dan OFF sesuai dengan penekanan tombol lampu pada aplikasi.

Pengujian berikutnya adalah pengujian sistem penghitung jumlah orang pada ruangan. Tujuan dari pengujian ini untuk mengetahui tingkat akurasi sistem dalam menghitung orang pada ruangan berdasarkan pembacaan sensor PIR yang terpasang pada pintu masuk dan pintu keluar. Data jumlah orang dan status alarm tampil pada aplikasi android yang terhubung melalui protokol MQTT, sehingga pada pengujian ini juga dapat diketahui tingkat akurasi pertukaran data antara publisher dan subscriber.

Kapasitas maksimal jumlah orang pada aplikasi Android diset sebanyak 10 orang. Maka jika jumlah orang lebih dari 10, alarm akan ON dan pada aplikasi akan tampil status alarm ON. Sebaliknya jika jumlah orang dalam ruangan kurang dari 10 maka alarm OFF. Data hasil pengujian sistem penghitung jumlah orang ditunjukkan pada Tabel 2.

\section{Tabel 2. Pengujian Penghitung Jumlah Orang}

\begin{tabular}{cccc}
\hline $\begin{array}{c}\text { Sensor PIR 1 } \\
\text { (Orang Masuk) }\end{array}$ & $\begin{array}{c}\text { Sensor PIR 2 } \\
\text { (Orang Keluar) }\end{array}$ & $\begin{array}{c}\text { Jumlah } \\
\text { Orang }\end{array}$ & Alarm \\
\hline 5 & & 5 & OFF \\
1 & 1 & 6 & OFF \\
& 1 & 5 & OFF \\
1 & & 4 & OFF \\
1 & & 5 & OFF \\
1 & & 6 & OFF \\
1 & 1 & 7 & OFF \\
& & 8 & OFF \\
1 & & 7 & OFF \\
1 & & 8 & OFF \\
& & 9 & OFF \\
& 1 & 10 & ON \\
& 1 & 9 & OFF \\
& 1 & 8 & OFF \\
& & 7 & OFF \\
\hline
\end{tabular}

Data pada Tabel 2 menunjukkan bahwa sistem dapat menghitung orang dengan baik dan sesuai. Pengujian yang dilakukan sebanyak 15 kali tersebut menunjukkan bahwa sistem dapat menghitung jumlah orang dalam ruangan berdasarkan orang masuk dan keluar yang terdeteksi oleh sensor PIR. Data jumlah orang yang tampil pada aplikasi Android yang terhubung melalui protokol MQTT menunjukkan jumlah yang sama dengan orang 
yang terdeteksi. Hasil pengujian menunjukkan juga alarm ON saat jumlah orang dalam ruangan melebihi kapasitas maksimal yang telah diset yaitu sama dengan atau lebih dari 10 orang. Sehingga dapat diketahui bahwa dari pengujian ini sistem memiliki akurasi 100\% dan data yang dikirimkan oleh yang dikirimkan publiser dan yang diterima subcriber mencapai kesesuaian $100 \%$.

\section{KESIMPULAN}

Sistem penghitung jumlah orang berbasis IoT telah berhasil diimplementasikan menggunakan sensor PIR sebagai pendeteksi orang, Raspberry Pi 3 sebagai kontroler, dan aplikasi android sebagai perangkat untuk memonitor jumlah orang dalam ruangan menggunakan protokol MQTT. Sistem dapat menghitung jumlah orang dalam ruangan dengan akurasi yang tinggi. Sistem dilengkapi juga dengan sistem peringatan yakni jika jumlah orang lebih dari kapasitas maksimal yang telah ditentukan maka alarm aktif.

Saran pengembangan sistem ini untuk penelitian selanjutnya adalah penghitung jumlah orang dapat dikembangkan untuk ruangan 1 pintu dan dapat memonitor lebih dari 1 ruangan. Aplikasi monitoring dapat dibuat berbasis aplikasi Android dan ditambahkan juga menggunakan web.

\section{UCAPAN TERIMA KASIH}

Penulis mengucapkan banyak terima kasih kepada Digitalent Kominfo dan Politeknik Manufaktur Bandung yang telah memfasilitasi penelitian ini, serta Politeknik Negeri Bandung yang telah menyelenggarakan seminar IRWNS sebagai sarana berbagi dan bertukar pikiran demi penyempurnaan penelitian ini.

\section{DAFTAR PUSTAKA}

[1] R. Pramana and R. Nababan, "Perancangan Perangkat Penghitung Jumlah Penumpang Pada Kapal Komersial Menggunakan Mikrokontroller," J. Sustain. J. Has. Penelit. dan Ind. Terap., vol. 8, no. 1, pp. 18-29, 2019, doi: 10.31629/sustainable.v8i1.569.

[2] R. G. Paramananda, H. Fitriyah, and B. H. Prasetio, "Rancang Bangun Sistem Penghitung Jumlah Orang Melewati Pintu menggunakan Sensor Infrared dan Klasifikasi Bayes," J. Pengemb. Teknol. Inf. dan Ilmu Komput. Univ. Brawijaya, vol. 1, no. 3, pp. 921-929, 2018.

[3] B. Arifin, E. N. Budisusila, and A. Cahyadi, "Penghitung jumlah Orang dengan Sensor Inframerah dan Modul LCD TFT sebagai Display," in Prosiding SNST, 2018, pp. 19-24.

[4] Y. Falih, R. E. Saputra, and C. Setianingsih, "Sistem Pendeteksi Jumlah Orang Dalam Ruangan Pada Kondisi Pandemi Covid-19 Berbasis Mikrokontroler Detection System for the Number of People in the Room During a Pandemic Covid-19 Based on Microcontroler," in $e$ -
Proceeding of Engineering, 2021, vol. 8, no. 2, pp. 2045-2052.

[5] L. C. Ratri, H. Fitriyah, and W. Kurniawan, "Deteksi Jumlah Penghuni Pada Ruangan Berpintu Untuk Smart Home Berbasis Arduino dan Sensor PIR," J. Pengemb. Teknol. Inf. dan Ilmu Komput., vol. 2, no. 1, pp. 36-43, 2018.

[6] M. Yakob, H. Saputra, R. A. Putra, and B. A. Uno, "Jurnal Pendidikan Fisika Universitas Muhammadiyah Makassar Design a System for Calculating the Number of People Passing Using the Arduino Uno Based PIR ( Passive Infrared Receiver ) Sensor Rancang Bangun Sistem Penghitung Jumlah Orang Melewati Pintu Mengg," J. Pendidik. Fis., vol. 7, no. 3, pp. 271-276, 2017.

[7] A. A. Sari et al., "Perancangan Dan Implementasi System Pendeteksi Pengunjung Pada Toko Berbasis Arduino," J. FTIK, vol. 1, no. 1, pp. 417-428, 2020.

[8] A. A. P. Y. S. D. Anggara Ady Prasetya, "Rancang Bangun Prototype Sistem Pencatatan Pengunjung Pada Stadion Sepak Bola Menggunakan Sensor Pir (Passive Infra Red)," J. Mhs. Fak. Sains dan Teknol., vol. 0, no. $0,2019$.

[9] M. A. Priastama, N. Alfarizal, and S. Rasyad, "Analisis Akurasi Sensor Proximity Optik sebagai Penjumlahan Orang Menggunakan Metode Bayes pada Alat Screening Protokol Kesehatan Covid-19," in Electro National Conference (ENACO), 2021, pp. 299-305.

[10] C. Hasiholan, R. Primananda, and K. Amron, "Implementasi Konsep Internet of Things pada Sistem Monitoring Banjir menggunakan Protokol MQTT," $J$. Pengemb. Teknol. Inf. dan Ilmu Komput., vol. 2, no. 12, pp. 6128-6135, 2018.

[11] Z. B. Abilovani, W. Yahya, and F. A. Bakhtiar, "Implementasi Protokol MQTT Untuk Sistem Monitoring Perangkat IoT," J. Pengemb. Teknol. Inf. dan Ilmu Komput. Univ. Brawijaya, vol. 2, no. 12, pp. 7521-7527, 2018.

[12] P. Alqinsi, I. J. Matheus Edward, N. Ismail, and W. Darmalaksana, "IoT-Based UPS Monitoring System Using MQTT Protocols," in Proceeding of 2018 4th International Conference on Wireless and Telematics, ICWT 2018, 2018, pp. 1-5, doi: 10.1109/ICWT.2018.8527815.

[13] Y. Aprinaldi and D. I. Saputra, "Sistem pemantauan dan pengisian cairan pada mesin hemodialisa berbasis IoT dengan protokol MQTT," JITEL (Jurnal Ilm. Telekomun. Elektron. dan List. Tenaga), vol. 1, no. 1, pp. 9-16, 2021, doi: 10.35313/jitel.v1.i1.2021.9-16.

[14] A. Saxena, M. Tyagi, and P. Singh, "Digital Outing System Using RFID and Raspberry Pi with MQTT Protocol," in Proceedings - 2018 3rd International Conference On Internet of Things: Smart Innovation and Usages, IoT-SIU 2018, 2018, pp. 1-4, doi: 10.1109/IoTSIU.2018.8519923.

[15] D. I. Saputra, G. M. Karmel, and Y. B. Zainal, "Perancangan dan Implementasi Rapid Temperature Screening Contactless dan Jumlah Orang Berbasis IOT dengan Protokol MQTT," J. Energy Electr. Eng., vol. 02, no. 01, pp. 20-30, 2020.

[16] H. Hamdani, J. Budiarto, and S. Hadi, "Sistem Kendali Peralatan Elektronik Rumah Tangga Berbasis Internet Of Things Menggunakan Protokol MQTT Jurnal BITe : Jurnal Bumigora Information Technology Jurnal BITe : Jurnal Bumigora Information Technology," J. BITe, vol. 2, no. 1, pp. 1-11, 2020, doi: 10.30812/bite.v2i1.799. 